\title{
GUIMARÃES ROSA NA CIDADE TIRADENTES anotações sobre a cidade do conhecimento
}

\author{
GiLSON SCHWARTZ
}

\begin{abstract}
Resumo: A partir da discussão da relação comunicação-transmissão, o artigo analisa a Cidade do Conhecimento, da USP, cujo projeto está centrado na construção de uma rede de comunicação voltada à produção compartilhada ou cooperativa de conhecimento.

Palavras-chave: produção de conhecimento; tecnologia de informação; educação.

Abstract: Grounded in a discussion of the relationship between communication and transmission, this article examines the University of São Paulo's City of Knowledge, a project that sets out to build a network of communication centered on the shared or joint production of knowledge.

Key words: production of knowledge; information technology; education.
\end{abstract}

\begin{abstract}
Eu atravesso as coisas - e no meio da travessia não vejo! - só estava era entretido na idéia dos lugares de saida e de chegada.
\end{abstract}

Guimarães Rosa (Grande sertão veredas)

\begin{abstract}
Comunicar é o ato de transportar uma informação no espaço; transmitir é transportar uma informação no tempo.

'Claro que para transmitir é preciso comunicar: mas é condição necessária, não suficiente. Esses verbos são irmãos, mas irmãos inimigos.'
\end{abstract}

Régis Debray (Les diagonales du médiologue Transmission, influence, mobilité, Bibliothéque Nationale de France, 2001)

$\Delta$ diferença entre transmitir e comunicar é da mesma ordem da que se pode fazer entre a travessia e os pontos de saída e de chegada, entre processo e estado, entre espaço e tempo.

A travessia não se vê nem é vista. No caso de Guimarães Rosa, é a rememoração confabulada dessa travessia que se torna o corpo de um processo de transmissão, pela leitura, que recria um tempo narrativo no qual o começo e o fim ce- dem lugar à primazia da própria travessia. Embora o livro, visto como um objeto sobre a mesa ou posto numa prateleira, seja apenas uma coisa delimitada, um registro, um dado.

A transformação do dado (um texto, uma estatística, uma fotografia, etc.) em conhecimento equivale a essa travessia que, no tempo mesmo em que ocorre, deixa atrás de si um rastro de coisas com começo, meio e fim.

Travar a travessia é bloquear a linguagem, o pensamento e a cultura. Ora, numa sociedade marcada pela hiperdominância da mídia, com aumento acelerado dos dejetos coisificados que se acumulam como dados, repetições, condicionamentos e memórias, até que ponto e por que razões ocorre esse bloqueio da linguagem?

Claro que não é pelo exame dos pontos de partida e de chegada desses processos midiáticos que se esclarecerá o assunto. Se McLuhan dizia que o meio é a mensagem, a questão crucial agora é examinar que tipos de travessia esse meio comporta - ou seja, até que ponto ele se presta a servir como espaço de transformação de dados em conhecimento e cultura.

Para sair do viés espacializante, estático e conservador da mera comunicação é preciso indagar portanto que tempos estão associados ao estágio mais avançado da trans- 
missão. O tempo da travessia, não como duração física mas como opção existencial com relação a que conhecimento e cultura se pretende produzir. É o "tempo real" das transmissões ao vivo da CNN e das transações financeiras globais ou é a história que, ao contrário do que sugeriu Fukuyama, não chegou ao fim porque as suas próprias condições de existência estão sendo repostas ao longo da nossa travessia vital e coletiva.

O projeto Cidade do Conhecimento, em curso no Instituto de Estudos Avançados da Universidade de São Paulo desde agosto de 2000 (www.cidade.usp.br), baseia-se na criação de uma rede de comunicação voltada à produção compartilhada ou cooperativa de conhecimento. Essa proposta foi aprovada pelo IEA, no final de 1999, como parte das atividades do Grupo de Estudos de Informação e Comunicação (www.ime.usp.br/ edic).

Pois bem: a requalificação do espaço-tempo graças à emergência do conceito de "tempo real" é uma das dimensões cruciais das transformações impulsionadas pelas novas tecnologias de informação. A outra é a reavaliação dos processos de socialização, sobretudo no que se refere ao estatuto do trabalho e, portanto, à economia política.

O nome acadêmico do projeto, Knowware: o EspaçoTempo da Sociedade do Conhecimento, é a crítica político-ideológica dos campos simbólicos gerados pelas principais inovações da economia política fundada no conhecimento. Essa sistematização será orientada pela noção de knowware, neologismo que atua como contraponto às noções convencionais de hardware, software e humanware, além de ser uma ironia metafórica com a palavra nowhere (lugar nenhum), indicativa do processo de apagamento das limitações espaciais imposto pela sociedade do conhecimento.

O projeto do IEA tem uma dimensão teórica, que consiste na revisão crítica da literatura sobre as tecnologias de informação e comunicação (TICs). A dimensão prática volta-se à construção de uma rede de comunicação que expresse e sirva de "campo de provas" para as visões, conceitos e recomendações examinadas na atividade teórica. Trata-se de criar um novo espaço público, uma comunidade de prática voltada à discussão das novas TICs.

Entre os desafios identificados preliminarmente como essenciais e que devem estar presentes no plano de construção dessa rede de comunicação destacam-se:

- mudança organizacional: mudança cultural e tecnológica em todas as organizações cujo sentido é a elaboração de práticas de produção de conhecimento como requisito para a inovação e a competitividade;
- convergência e interatividade: embora seja evidente que as novas TICs constituem desdobramentos na história das comunicações (rádio, telefonia, televisão, etc.) e da computação (protocolos, sistemas de armazenamento e processamento, ubiqüidade dos aparatos, etc.), o aspecto mais relevante e ainda em fase de identificação, exploração e criação é o da convergência dessas várias mídias e suportes tecnológicos sob o signo de uma interatividade sem precedentes, sugerindo até que já nem se trata apenas de processos de comunicação, mas de novas relações sociais e processos econômicos (ou seja, de criação e acumulação de valor);

- conhecimento tácito: essas novas relações e processos, centrados na conversão de informação em conhecimento, exigem e estimulam a percepção de várias modalidades ou mesmo novas imagens do conhecimento, com destaque para o que se denomina conhecimento tácito, ou seja, aquele que resulta do processo mesmo de comunicação, nem sempre sendo passível de registro/codificação/explicitação nos moldes cristalizados nas organizações existentes.

A rede que o IEA da USP está construindo enfrenta essas três dimensões simultaneamente. É portanto um esforço interdisciplinar que requer conhecimentos e tem impactos tanto no campo da tecnologia de informação e conhecimento quanto em tecnologias educacionais e em diversas áreas das ciências humanas e sociais aplicadas.

No campo da mudança cultural e organizacional, o maior imperativo é o da constituição de sistemas econômicos e sociais em que se combinam a competição e a cooperação (um termo que vem sendo usado com freqüência é o da "coopetição").

Para alcançar esse tipo de configuração, evidentemente a mudança não pode estar restrita a uma dada organização (uma empresa, uma escola, etc.) mas precisa necessariamente ser sistêmica. É o que se pretende com o uso cada vez mais difundido da noção de redes, em sentido literal e sobretudo metafórico, simbólico.

No caso da Cidade do Conhecimento, a rede em construção procura antes de mais nada propor novas formas de interação entre os mundos da escola e do trabalho, criando conexões entre estudantes de ensino médio, alunos de graduação e pós-graduação e profissionais já atuando no mercado de trabalho.

Considerando que o tema prioritário nessa fase de transição global é o da empregabilidade, a rede de comunicação assim estabelecida tem como desafio central a pro- 
moção de usos socialmente inclusivos das tecnologias de informação. Não por acaso o projeto inaugural na formação de redes cooperativas é o Dicionário do trabalho vivo, criação coletiva de um conhecimento sobre as condições de trabalho, associada à rede de Observatórios do Futuro do Trabalho e financiada pela Secretaria do Emprego e Relações do Trabalho do governo estadual de São Paulo, em convênio assinado por Walter Barelli no ano 2000.

Nessa rede, o aluno de ensino médio, graduação ou pósgraduação desenvolve um projeto cooperativo temático contando com a participação voluntária de um mentor, preferencialmente um profissional (empregado, desempregado ou aposentado), mas que pode ser também alguém num estágio mais avançado de formação, como um aluno de pós-graduação que assume a condição de mentor de um aluno de ensino médio.

Duas iniciativas complementares têm como objetivos adensar e legitimar a rede entre alunos e profissionais. $\mathrm{Na}$ comunidade escolar, o IEA oferece um curso de extensão universitária (Educar na Sociedade da Informação) sobretudo para integrar à rede as lideranças da comunidade educacional do ensino médio e fundamental (professores, diretores, etc.), com a parceria da faculdade de educação e a participação de pesquisadores de várias áreas da universidade.

De modo análogo, está em preparação um ciclo de extensão universitária para as lideranças do mundo das organizações (empresas, órgãos de governo e não-governamentais), fundamentado nos impactos das novas tecnologias de informação e comunicação nos processos de gestão de recursos humanos, sistemas de informação, inteligência competitiva e temas correlatos no âmbito da "nova economia" em seus impactos sociais. São as Oficinas de Design Social.

Nos dois cursos, o que se procura em última análise não é apenas oferecer mais disciplinas e vagas na universidade, mas sobretudo estabelecer novas formas de conexão entre as organizações e a universidade, supondo que as várias comunidades envolvidas precisam mudar de modo simultâneo e interativo. Aliás, também se buscam novas formas mais cooperativas de conexão internamente à Universidade de São Paulo.

Quando se fala, portanto, em convergência e interatividade, está em questão não só a dimensão tecnológica da convergência digital e da interatividade on-line. Trata-se de um processo de convergência social (no sentido de criação de novas formas de cooperação e reconfiguração do contrato social) e interatividade política e institucional (democratizando a produção de conhecimento e promovendo a informação livre).

Esse processo não deve ser restrito às formas estabelecidas de reconhecimento acadêmico (ocorreria inclusão digital, mas com exclusão cognitiva ou epistêmica). Tanto no mundo da administração de empresas quanto no mundo das práticas pedagógicas vem ganhando importância o conhecimento tácito, que requer resultados não restritos às formas convencionais de certificação (monografias, mestrados, doutorados) mas com outros registros inclusos (depoimentos, imagens, vídeos, relatos, narrativas, eventos, etc.).

É, então, decisivo que as interações entre alunos e profissionais possam contar com o suporte e a perspectiva de produção de resultados em várias mídias. Com isso, o projeto insere-se na guerra contemporânea pela ocupação de territórios virtuais, algo que se poderia legitimamente comparar a uma "reforma agrária do ar" ("ar", no caso, refere-se ao espectro de freqüências eletromagnéticas que constitui patrimônio público e que vem a ser ocupado por meio de concessões, cuja distribuição tem sido ferramenta de manipulação política e negociações clientelistas).

Esquematicamente, a Cidade do Conhecimento proposta pelo IEA é uma rede de comunicação mediada pela universidade e formada por quatro redes associadas, que se encontram na figura apresentada a seguir.

O desafio é ampliar os impactos da universidade pública na formação da cidadania, numa época em que ser cidadão ou "estar incluído" são praticamente sinônimos de ter acesso a conhecimento. Mais que ter acesso, aliás, é preciso que cada indivíduo, organização e empresa sejam capazes de produzir conhecimento.

É uma oportunidade para que a universidade pública seja reconhecida em seus valores mais essenciais, mas sob um novo formato institucional, mediado pelas novas tecnologias de informação e comunicação. Tecnologias que oferecem novas possibilidades de transparência e negociação entre todos os indivíduos que participam dessa comunidade.

O desafio político é criar novas formas de democratizar a sociedade contemporânea. A Cidade do Conhecimento, projeto do Instituto de Estudos Avançados da Universidade de São Paulo, enfrenta esse desafio ao definir como seu tema o surgimento de formas inovadoras de organização no âmbito da economia do conhecimento. Pode-se ir mais longe: está nascendo um novo "modo de produção" (de conhecimento) em escala global e o país 


\section{FIGURA 1}

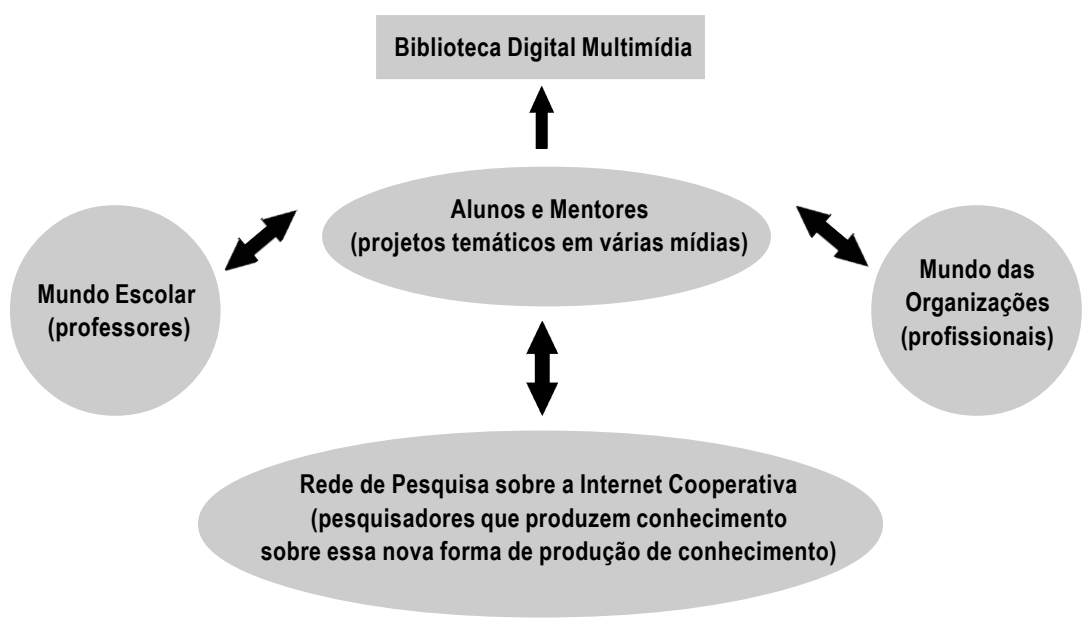

precisa integrar-se a ele com autonomia e capacidades críticas e criativas.

Na prática, o desafio é construir comunidades de conhecimento, ou seja, espaços públicos onde se produz conhecimento coletivamente, apontando para a Internet e, de modo geral, para as redes como suportes de uma nova era de criatividade empresarial, institucional e política.

Onde e como enfrentar esse desafio senão na universidade pública, em especial na Universidade de São Paulo, uma das maiores e mais produtivas do mundo? O Instituto de Estudos Avançados é a pedra fundamental dessa cidade, nova teia que já conta com o apoio dos jornais Folha de S.Paulo, O Estado de S.Paulo, Gazeta Mercantil, Valor Econômico e da TV Cultura. Obviamente, a rede está aberta a todos os outros grupos de mídia. ONGs, escolas do ensino médio, associações e sindicatos poderão contar com um novo acesso à universidade pública. Na USP, a universidade está se mobilizando, de estudantes individuais a entidades estudantis, passando por diretores de faculdades e de unidades especiais, como o Centro de Computação Eletrônica (CCE), a Coordenadoria de Comunicação Social (CCS) e o Cecae (Coordenadoria Executiva de Cooperação Universitária e de Atividades Especiais). Escolas de ensino médio, alunos de graduação e pós-graduação estarão nessa rede voltada à produção coletiva, em praça pública, de conhecimento permanentemente compartilhado.

A Cidade do Conhecimento será uma rede de comunicação posta a serviço do contato direto entre alunos de vários níveis escolares e profissionais em níveis igualmente variados de inserção no mercado de trabalho. Surgirão “mentores". Por exemplo, um jornalista numa redação que discute com alunos de ensino médio ou graduação o que é o fazer jornalístico. Também engenheiros, economistas, sociólogos, médicos, empreendedores e trabalhadores poderão compartilhar, diretamente, conhecimento e informações sobre suas áreas de atividade com alunos que, um dia, chegarão ao mercado de trabalho.

Mas o aluno ou aprendiz também assumirá, em muitos casos, a condição de mentor. Um executivo que lida diariamente com operações de câmbio num banco, por exemplo, poderá buscar uma parceria com um aluno de graduação ou pós-graduação que lhe indique um texto, digamos, sobre crise cambial na América Latina.

$\mathrm{Na}$ prática, a produção do conhecimento ocorre mediada por um diálogo. Esse diálogo é a base para a construção de uma sociedade mais justa e com mais oportunidades de emprego.

A rede que buscamos será um produto de ações voluntárias, mas não no sentido da caridade, do assistencialismo que "visita" os excluídos e sim como algo mais próximo da militância, do exercício permanente de aprendizado e crítica, mobilização e confronto entre idéias e projetos, dentro e fora da universidade pública.

$\mathrm{Na}$ prática, a rede que nasce na USP será um canal de acesso de alunos, professores e profissionais de fora da USP a um novo espaço público em que o conhecimento é produzido de forma compartilhada. Espaço que, aliás, servirá como território de experimentação na avaliação e desenvolvimento de metodologias para o uso de tecnologias na sociedade - questão que inclui mas vai muito 
além do chamado "ensino a distância". Todos os projetos envolvendo mentores, os cursos e outras atividades terão resultados que ficarão disponíveis para acesso público.

Ao mesmo tempo, os participantes da Cidade do Conhecimento serão mobilizados para refletir de modo continuado sobre a importância do conhecimento compartilhado e da informação pública.

Buscamos um aprendizado sobre criação e gerenciamento de comunidades virtuais que produzirá resultados acadêmicos e políticos, além de benefícios empresariais e organizacionais no setor público e no setor privado.

Mas, ao mesmo tempo, caberá a cada indivíduo explorar os recursos que a rede torna disponível. Num momento em que várias iniciativas importantes no campo da expansão da infra-estrutura de telecomunicações estão sendo promovidas no Brasil, em especial a informatização da rede escolar, a USP oferece à comunidade um espaço privilegiado para a produção pública de conteúdos que a tornem mais inteligente, crítica, democrática e criativa possível fazendo uma travessia por mídias que existem apenas na medida em que se desenvolvem novas tecnologias.

As novas tecnologias de informação e comunicação criam novas possibilidades de vida e novas oportunidades de ação política. O resultado estratégico que se espera desse projeto é contribuir para a formulação de estratégias e políticas de inserção ativa da economia brasileira no espaço competitivo global, por meio do aumento do grau de inteligência que apenas a democratização do conhecimento pode produzir.

Será que algum dia lerão Guimarães Rosa os sertanejos de Cidade Tiradentes?

Gilson Schwartz: Professor visitante do Instituto de Estudos Avançados da USP e Diretor Acadêmico do projeto Cidade do Conhecimento $<$ http://www.cidade.usp.br>. 